\title{
Microwave drying in fluidized bed to dehydrate microencapsulated Saccharomyces cerevisiae cells. Temperature control strategies
}

\section{Mardaras, J.9; Lombraña, J.I. ${ }^{\text {a*} ; V i l l a r a ́ n, ~ M . C . ~}{ }^{\text {b }}$}

${ }^{a}$ Department of Chemical Engineering. Faculty of Science and Technology, University of the Basque Country,P.O Box 644. 48080 Bilbao (Spain)

${ }^{\mathrm{b}}$ Health \& Food Area.Health Division, TECNALIA Research \& Innovation. 01510 Miñano, Alava (Spain)

*E-mail of the corresponding author: ji.lombrana@ehu.es

\begin{abstract}
Alginate microcapsules containing cell yeasts of the species Saccharomyces cerivisae, used as a reference microorganism, were studied here to improve the protection of cell activity during food processing. Here a novel drying process was proposed to optimize processing conditions.

The dehydration of microcapsules by microwaves and under near fluidizing conditions (NFMD), allows performing dehydration employing lower temperatures to maintain high viability levels and a high quality end product. Thus, strategies based on the combination of different thermal gradients and processing temperatures were analysed through a series of NFMD experiments.
\end{abstract}

Keywords: microwave drying, fluidization, probiotics, cell viability. 


\section{Introduction}

In this work, the novel Near Fluidizing Microwave Drying (NFMD) process is studied to avoid some of the problems with lyophilization and spray drying. Microwave heating adequately controlled is specially recommended for drying. Through this process, the heat is generated inside the microcapsules, causing a thermal gradient from inside out, which favours the elimination of the moisture [1]. Microwave drying is a technology that is being developed widely in the food industry [2]. Drying of the microcapsules through the application of microwaves presents as primary characteristic, the inverse temperature gradient, favouring the drying of the microcapsules from inside out, as opposed to conventional drying methods. The application of this inverse temperature gradient involves much lower temperatures and operating times [3]; [4]. Based on previous kinetic studies of the microwave drying operation, three perfectly differentiated phases during the dehydration of microcapsules have been found [5].

As an extension of the study, here the effect of control variables in the applied energy for the drying process of microcapsules were studied. Several operating conditions were analysed combining different values of thermal levels of control variables: air and product temperature. Finally, the viability of each thermal level applied by microwaves was compared with the results obtained by freeze-drying.

\section{Materials and Methods}

\subsection{Preparation of microcapsules and viability analysis}

Microcapsules were prepared following a variant to that indicated in the bibliography [6]. In this work, dry yeast extract (Saccharomyces cerevisiae, ZYMAFLORE ${ }^{\circledR}$ ) supplied by LAFFORT (France), containing an active cell concentration higher than $210^{10} / \mathrm{g}$, was used as cell culture material. Capsules were extracted from the solution by filtration and, once eliminated the superficial water, they were conveniently packaged and stored for $18 \mathrm{~h}$ in covered traysduring18 $\mathrm{h}$ in a freezer at $4{ }^{\circ} \mathrm{C}$ until the start of the drying experiment. This leads to initial moisture content between 7.1 and $7.3 \mathrm{~g}$ water/g d.s. in all the cases.

The evaluation of viable encapsulated yeast was carried out by homogenizing $0.1 \mathrm{~g}$ of filtered microsphere slurry in $10 \mathrm{~mL}$ of sodium citrate $0.1 \mathrm{M}$ for $10 \mathrm{~min}$ and stirred. The plates were incubated for 2 days at $37^{\circ} \mathrm{C}$ and the encapsulated yeast enumerated as cfu/g d.s.

\subsection{Drying experiments}


The experiments were carried out according to the procedure NFMD, consisting of dry cell capsules, under fluidizing conditions, through the supply of heat by microwaves. Microwave power was regulated during the drying process in order to achieve certain values of temperature in the microcapsules and the temperature of the air being introduced into the bed of particles.

Nine thermal strategies were tested in this study combining three levels for the air temperature with other three levels for the product surface temperature through temperature $T_{\mathrm{f}}$ (Table 1$)$. The inlet air temperature levels considered were: $5^{\circ} \mathrm{C}$, room temperature $\left(20^{\circ} \mathrm{C}\right)$ and $40^{\circ} \mathrm{C}$. The different experiments were defined on the basis of combining these three air temperature levels with three different target surface temperatures of the microcapsules. Since it was difficult to measure the temperature of the microcapsules directly, $T_{\mathrm{f}}$ was controlled instead, measuring the temperature of the air film in contact by a fiber optic probe placed inside the microcapsules bed.

Table 1 Definition of the thermal levels in the NFMD experiments.

\begin{tabular}{|c|c|c|c|c|c|c|c|c|}
\hline & \multicolumn{3}{|c|}{ Phase I } & \multicolumn{3}{|c|}{ Phase II } & \multirow[t]{2}{*}{ Phase III } & \multirow[t]{2}{*}{ Code } \\
\hline Exp. & $\mathbf{T}_{\text {in }}{ }^{*}$ & $\mathbf{T}_{\mathrm{f}}^{*}$ & $\mathbf{T}_{\mathrm{s}}{ }^{*}$ & $\mathbf{T}_{\text {in }}{ }^{*}$ & $\mathbf{T}_{\mathrm{f}}^{*}$ & $\mathbf{T}_{\mathbf{s}}^{*}$ & & \\
\hline 1 & 5 & 10 & 15 & 5 & 17.5 & 30 & & $\mathrm{Ll} / \mathrm{Ml}$ \\
\hline 2 & 5 & 17.5 & 30 & 20 & 25 & 30 & $50 \mathrm{c} / \mathrm{b}$ donging & $\mathrm{Ml} / \mathrm{Mm}$ \\
\hline 3 & 5 & 10 & 15 & 40 & 27.5 & 15 & 5 C/n decreasing & $\mathrm{Ll} / \mathrm{Lm}$ \\
\hline 4 & 20 & 25 & 30 & 5 & 17.5 & 30 & & $\mathrm{Mm} / \mathrm{Hl}$ \\
\hline 5 & 20 & 17.5 & 15 & 20 & 25 & 30 & rate of $T_{\text {in }}$ & $\mathrm{Lm} / \mathrm{Ml}$ \\
\hline 6 & 20 & 17.5 & 15 & 40 & 42.5 & 45 & $\left(\right.$ from $\left.10^{\circ} \mathrm{C}\right)$ & $\mathrm{Lm} / \mathrm{Hm}$ \\
\hline 7 & 20 & 17.5 & 15 & 20 & 32.5 & 45 & (trom $\left.40^{\circ} \mathrm{C}\right)$ & $\mathrm{Lm} / \mathrm{Hh}$ \\
\hline 8 & 40 & 27.5 & 15 & 40 & 42.5 & 45 & & $\mathrm{Lh} / \mathrm{Hh}$ \\
\hline 9 & 40 & 35.5 & 30 & 20 & 32.5 & 45 & & $\mathrm{Mh} / \mathrm{Hm}$ \\
\hline
\end{tabular}

The code used in Table 1 refers to the thermal conditions employed in Phases I and II. The first two letters correspond to Phase I and the other two, separated by a slash, to Phase II. At each phase, the first capital letter refers to the target temperature for the surface $\left(T_{s}^{*}\right): \mathrm{L}=15^{\circ} \mathrm{C}$ (Low), $\mathrm{M}=30^{\circ} \mathrm{C}$ (Medium), and $\mathrm{H}=45^{\circ} \mathrm{C}$ (High). The second letter refers to the inlet air temperature $T_{\text {in }}{ }^{*}$ using the same but in small letters: $\mathrm{l}=5^{\circ} \mathrm{C}, \mathrm{m}=20^{\circ} \mathrm{C}$ and $\mathrm{h}=40^{\circ} \mathrm{C}$. Thus, in Experiment $3(\mathrm{Ll} / \mathrm{Lm})$, low thermal level was applied either for Phase I or II, except for the thermal gradient in Phase II, where a $40{ }^{\circ} \mathrm{C}$ inlet air temperature was applied.

\section{Results and discussion}

The air velocity was used as indicator variable to define the phase boundaries, rather than the water content, which would have been much less accessible for following the process. 
Microwave drying in fluidized bed to dehydrate microencapsulated Saccharomyces cerevisiae cells. Temperature control strategies

\subsection{Variation of the minimum fluidization velocity}

The microcapsules obtained as described in the previous section had an initial moisture content of around $85 \%(\mathrm{X}=0.85 \pm 0.03)$ at the beginning of the drying. Under these conditions, microcapsules have a high adherence so that, initially, the experimental minimum fluidization velocity $u_{\mathrm{mf}}^{*}$ of the bed was considerably higher than that obtained theoretically.

Initially, the experimental minimum fluidization velocity, $u^{*}$ mf, was $1.39 \mathrm{~m} / \mathrm{s}$, about 3 times higher than the theoretical minimum fluidization velocity, $u_{\mathrm{mf}}$, obtained in accordance to the previous equations. Velocity decreases rapidly as drying progresses, while the theoretical value $u_{\mathrm{mf}}$ decreases slowly only affected by the decrement in density and particle size $d_{\mathrm{p}}$ along the drying. When the humidity of the particles reaches a value around $X=0.5$, the microcapsules lose the adherence shown at the beginning of the process so that the experimental minimum fluidization velocity becomes equal to the theoretical. In such a situation: $u_{\mathrm{mf}}^{*}=u_{\mathrm{mf}}=0.29 \mathrm{~m} / \mathrm{s}$ (see Table 2 ) and it was set in this study as a reference for the definition of the end of Phase II or beginning of Phase III. From this moment, the residual moisture of the particles is removed exclusively by convective heating (microwave is off).

Table 2. Data of $X, u_{m f}, d_{p}$ and time in the transitionPhase II-III, in the different NFMD strategies

\begin{tabular}{c|cccc|ccc}
\hline \multirow{2}{*}{$\begin{array}{c}\text { Heatings } \\
\text { trategy }\end{array}$} & \multicolumn{5}{|c|}{ Phase II } & \multicolumn{3}{c}{ Phase III } \\
\cline { 2 - 8 } & $\mathbf{t}(\mathbf{m i n})$ & $\boldsymbol{X}^{(\mathbf{1}}$ & $\boldsymbol{d}_{\boldsymbol{P}(\mathbf{m})}$ & $\boldsymbol{u}_{\boldsymbol{m} \boldsymbol{f}^{*} / \boldsymbol{u}_{\boldsymbol{m} \boldsymbol{f}^{(\mathbf{2}}}}$ & $\mathbf{t}(\mathbf{m i n})$ & $\boldsymbol{X}^{\mathbf{1}}$ & $\boldsymbol{d}_{\boldsymbol{P}}(\mathbf{m})$ \\
\hline $\mathbf{L l} / \mathbf{M l}$ & 35 & 0.44 & $1.69 \mathrm{E}-03$ & $0.30 / 0.32$ & 275 & 0.045 & $1.13 \mathrm{E}-03$ \\
\hline $\mathbf{M l} / \mathbf{M m}$ & 30 & 0.49 & $1.76 \mathrm{E}-03$ & $0.30 / 0.30$ & 195 & 0.070 & $1.16 \mathrm{E}-03$ \\
\hline $\mathbf{L l} / \mathbf{L m}$ & 18 & 0.55 & $1.86 \mathrm{E}-03$ & $0.38 / 0.28$ & 240 & 0.072 & $1.16 \mathrm{E}-03$ \\
\hline $\mathbf{M m} / \mathbf{H l}$ & 25 & 0.49 & $1.76 \mathrm{E}-03$ & $0.30 / 0.30$ & 240 & 0.070 & $1.16 \mathrm{E}-03$ \\
\hline $\mathbf{L m} / \mathbf{M l}$ & 25 & 0.57 & $1.88 \mathrm{E}-03$ & $0.40 / 0.30$ & 235 & 0.070 & $1.16 \mathrm{E}-03$ \\
\hline $\mathbf{L m} / \mathbf{H m}$ & 20 & 0.39 & $1.63 \mathrm{E}-03$ & $0.30 / 0.30$ & 210 & 0.071 & $1.16 \mathrm{E}-03$ \\
\hline $\mathbf{L m} / \mathbf{H h}$ & 23 & 0.48 & $1.75 \mathrm{E}-03$ & $0.28 / 0.32$ & 240 & 0.078 & $1.17 \mathrm{E}-03$ \\
\hline $\mathbf{L h} / \mathbf{H h}$ & 15 & 0.54 & $1.84 \mathrm{E}-03$ & $0.28 / 0.36$ & 240 & 0.081 & $1.18 \mathrm{E}-03$ \\
\hline $\mathbf{M h} / \mathbf{H m}$ & 20 & 0.5 & $1.78 \mathrm{E}-03$ & $0.32 / 0.30$ & 240 & 0.072 & $1.16 \mathrm{E}-03$ \\
\hline
\end{tabular}

${ }^{1}$ Units of $X_{\text {in }}$ and $X$ : g water/g w.b. ${ }^{2}$ Units of $u_{\mathrm{mf}}{ }^{*}$ and $u_{\mathrm{mf}}: \mathrm{m} / \mathrm{s}$

An acceptable correspondence of the moisture content $\mathrm{X}$ with the minimum fluidization velocity values used in each phase can be seen in Table 2. Thus, the average values of $X$ corresponding to the end of Phase I and II, for all the experimental conditions tested, were 0.75 and 0.49 with a standard deviation of 0.040 and 0.051 , respectively. 


\subsection{Drying kinetics analysis}

In Figure 1, the mass loss profiles of NFMD Experiments 1 and 2, in terms of $M R$ (moisture ratio dry basis), are compared with spray-drying and freeze-drying of product with similar water content. The drying time spent in the NFMD is clearly lower than freeze-drying and only a few minutes longer than the time observed in spray drying (about $100 \mathrm{~min}$ ) but the thermal levels applied are considerable. Consequently, NFMD presents very favourable characteristics for the drying of thermosensible materials with similar efficiencies to those obtained by spray-drying, taking into account the duration of cycles and power consumption [7].

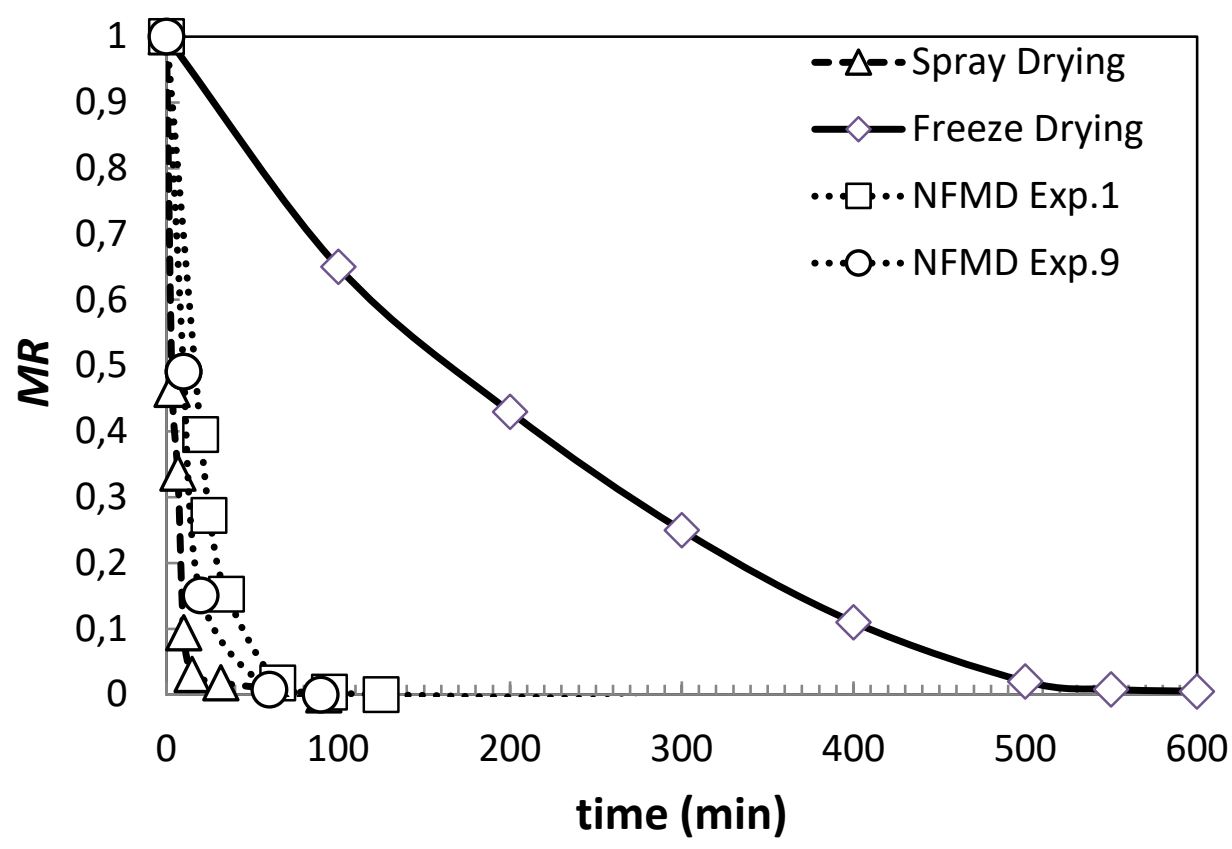

Figure 1. Drying kinetics of NFMD compared to freeze-drying (Rudy et al., 2015) and spray-drying.

When analyzing the thermal profiles, it is necessary to take into account the strong reduction of mass during Phases I and II that directly affects the thickness of the bed through a reduction of the particle size, as shown in Table 2 above. An idea of the reduction of the size associated with the water loss is shown in Figure 2 for Experiment $7(\mathrm{Lm} / \mathrm{Hm})$. Thus, Figure 2a and $2 b$ correspond to the start and end of Phase I, where one can see the important size difference with respect to the rest of the drying (Figure 2c and 2d). As a result, an important reduction 
in the thickness of the bed, up to a $25 \%$ of the initial value, was observed at the end of Phase II.
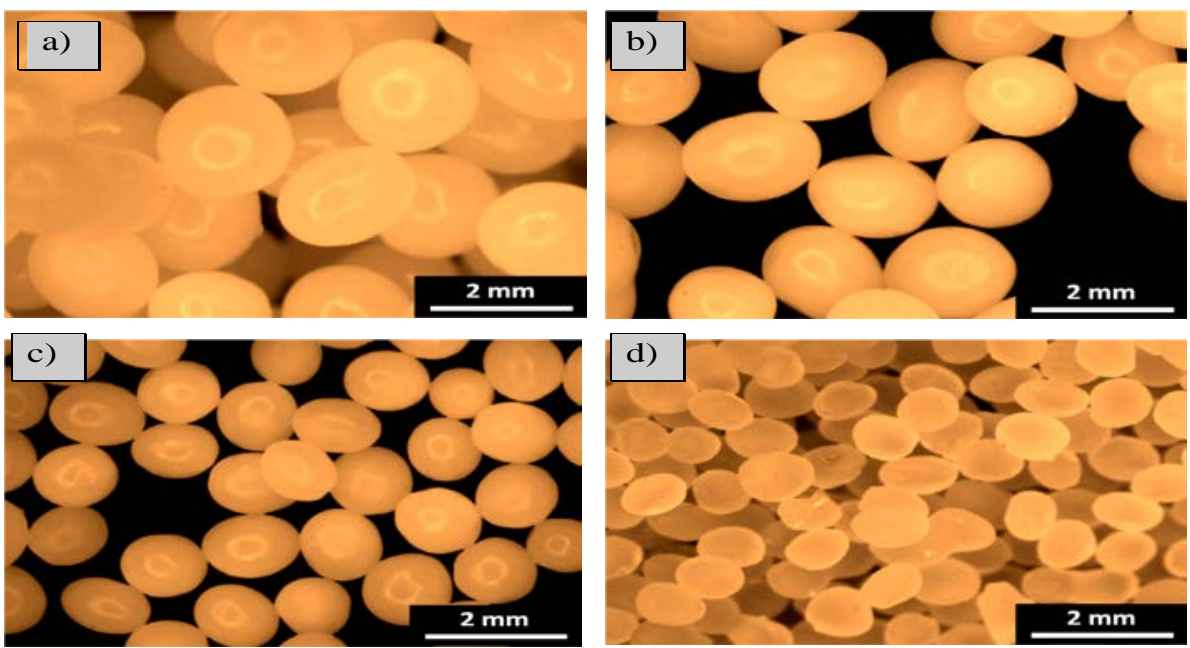

Fig. 2 Micrograph of the microcapsules at different drying times for Experiment 7 (Lm/Hm): a) $X i n=0.80, d p=2.12 \mathrm{~mm}$; b) $X=0.51, d p=1.8 \mathrm{~mm}$; $) X=0.24, d p=1.4 \mathrm{~mm}$; $) X=0.05, d p=1.1 \mathrm{~mm}$.

\subsection{Quality of the dehydrated product}

The lower the water activity, the better the stability of the dry food product, but in very low water activities, the oxidisation of membrane lipids can also reduce viability [8].

The moisture content was determined by the Karl-Fischer method. Results were obtained on wet basis, expressed as percent $(K F)$ that permits to determine the dry solid fraction taking into account the mass loss during drying. The results of $K F$ from each experiment were used to confirm the dry solid fraction of capsules.

The probiotic viability or survival ratio (in \%) of the microorganisms in each experiment is defined accorindg to Chávarri et al.[6]. It is based on a count of colony forming units (cfu), taking the log values in the initial sample $\left(c f u_{0}\right)$ and after drying $\left(c f u_{f i n}\right)$. According to Table 3 , the average data of drying rate for each experiment, the time of processing, water activity, $K F$, and the survival \% of the overall process are shown at the end of each drying conditions. The NFMD experiments were made by triplicate in order to analyse the effect of possible process variability on the viability results. In Table 3, one can see that the standard error of the survival values were in all cases lower than $1.6 \%$.This proves a good process control with the used operating variables and the subsequent reproducibility of experiments. 
Table 3 Quality parameters obtained for all experiments.

\begin{tabular}{cccccccc}
\hline Exp. & $\boldsymbol{r}_{\text {I-II }}$ & $\boldsymbol{M}_{\text {fin II }}$ & $\boldsymbol{r}_{\text {global }}$ & time (min) & $\boldsymbol{K F}$ & Survival (\%) & Code \\
\hline $\mathbf{1}$ & 0,114 & 0,783 & 0,017 & 275 & 6,726 & $74.42 \pm 1.01$ & $\mathrm{Ll} / \mathrm{Ml}$ \\
$\mathbf{2}$ & 0,126 & 0,946 & 0,024 & 195 & 7,522 & $96.00 \pm 1.37$ & $\mathrm{Ml} / \mathrm{Mm}$ \\
$\mathbf{3}$ & 0,219 & 1,245 & 0,021 & 240 & 7,706 & $93.83 \pm 0.28$ & $\mathrm{Ll} / \mathrm{Lm}$ \\
$\mathbf{4}$ & 0,184 & 0,945 & 0,023 & 240 & 7,577 & $88.65 \pm 0.04$ & $\mathrm{Mm} / \mathrm{Hl}$ \\
$\mathbf{5}$ & 0,163 & 1,309 & 0,023 & 235 & 7,458 & $91.78 \pm 0.03$ & $\mathrm{Lm} / \mathrm{Ml}$ \\
$\mathbf{6}$ & 0,198 & 0,646 & 0,022 & 210 & 7,599 & $87.69 \pm 0.15$ & $\mathrm{Lm} / \mathrm{Hm}$ \\
$\mathbf{7}$ & 0,159 & 0,907 & 0,019 & 240 & 8,414 & $77.62 \pm 0.54$ & $\mathrm{Lm} / \mathrm{Hh}$ \\
$\mathbf{8}$ & 0,349 & 1,184 & 0,026 & 240 & 8,830 & $74.44 \pm 1.13$ & $\mathrm{Lh} / \mathrm{Hh}$ \\
$\mathbf{9}$ & 0,254 & 0,992 & 0,025 & 240 & 7,726 & $55.00 \pm 0.98$ & $\mathrm{Mh} / \mathrm{Hm}$ \\
Lyo. & & & 0,007 & 720 & 8,855 & $91.18 \pm 1.44$ & - \\
\hline
\end{tabular}

"Units: $r_{\mathrm{I}, \text { II }}$ and $r_{\text {global }}: \mathrm{g} \mathrm{H}_{2} \mathrm{O} / \mathrm{g}$ d.s. min, $M_{\text {fin III }}$ g $\mathrm{H}_{2} \mathrm{O} / \mathrm{g}$ d.s.

\section{Conclusions}

The NFMD process has proved to be a feasible technology for microencapsulated microorganisms dehydration. The global value of drying rate was in all NFMD cases around $0.02 \mathrm{~g}$ water/g d.s., spite of the significant differences when referring Phases I and II. The long duration of Phase III dilutes somehow the differences of preceding phases.

The operating conditions applied and the temperature gradient from product to air or viceversa generate a convective heat flow that leads to an extra heat contribution (medium air temperature; i.e. Experiment 1) or heat loss (low air temperature; i.e. Experiment 9). Despite the negative effect on energy consumption that occurs when the air temperature is low or medium, this circumstance seems to favour the quality of the dehydrated product as in Experiment 2, showing high survival values of 96\%.

\section{References}

[1] Lombraña, J.I., Rodriguez. R., Ruiz. U. Moisture Microwave-Drying of Sliced Mushroom. Analysis of Temperature Control and Pressure. Innovative Food Science \& Emerging Technologies 2010, 11, 652-660

[2] Kudra, T. Mujumdar, A,S. Advanced Drying Technologies. Marcel Dekker, Basel, Switzerland, 2009.

[3] Feng, H., Yin, Y.and Tang, J. Microwave Drying of Food and Agricultural Materials: 
Basics and Heat and Mass Transfer Modelling. Food Engineering Reviews 2012, 4, 89106.

[4] Li, Z., Raghavan, G.S.V., Wang, N., Vigneault, C. Drying rate control in the middle stage of microwave drying. Journal of Food Engineering 2011, 104, 234-238.

[5] Ruiz, U., Lombraña, J.I. (). Effects of the inverse temperature gradient in microwave drying kinetics of pasta.17th International Drying Symposium, Magdeburg, Germany, 2010, 2098-2104.

[6] Chávarri, M., Marañón, I., Ares, R., Ibáñez, F. C., Marzo, F., Villarán, M. d. C. Microencapsulation of a probiotic and prebiotic in alginate-chitosan capsules improves survival in simulated gastro-intestinal conditions. International Journal of Food Microbiology 2010, 142(1-2), 185-189.

[7] Schmitz-Schug, I., Kulozik, U., Foerst, P. Modeling spray drying of dairy products Impact of drying kinetics, reaction kinetics and spray drying conditions on lysine loss. Chemical Engineering Science 2016, 141, 315-329.

[8] Viernstein, H., Raffalt, J., Polheim, D. Stabilisation of probiotic microorganisms. In: Nedovic, V., Willaert, R. (Eds.), Applications of Cell Immobilisation Biotechnology. Springer, Dordrecht, The Netherlands, 2005, 439-455. 